Max-Planck-Institut für demografische Forschung

Max Planck Institute for Demographic Research

Konrad-Zuse-Strasse 1 - D-18057 Rostock · GERMANY

Tel +49 (0) 3812081 - 0; Fax +49 (0) 3812081 - 202;

http://www.demogr.mpg.de

MPIDR WORKING PAPER WP 2006-028

AUGUST 2006

\title{
Report on the external validation of the \\ "Education and Employment Survey" on Russia
}

Eugeny Soroko
Dirk Konietzka (konietzka@demogr.mpg.de)

This working paper has been approved for release by: Jan M. Hoem (hoem@ demogr.mpg.de)

Head of the Laboratory of Contemporary European Fertility and Family Dynamics.

(C) Copyright is held by the authors.

Working papers of the Max Planck Institute for Demographic Research receive only limited review. Views or opinions expressed in working papers are attributable to the authors and do not necessarily reflect those of the Institute. 


\title{
Report on the external validation of the "Education and Employment Survey" on Russia
}

\author{
Eugeny Soroko ${ }^{1}$, Dirk Konietzka ${ }^{2}$
}

1. Introduction: EES data examined ${ }^{3}$

This report has been prepared for the "Education and Employment"-project (EES). The survey was conducted in 2005 and it represents a sub-sample of the Russian "Generations and Gender"-Survey (GGS) which was carried out in 2004. The EES contains 6455 persons, of which 2460 are males and 3995 are females. The EES questionnaire consists of 199 items on education and employment careers as well as on personal social and demographic indicators.

The aim of this report is to provide an external validation of the EES. For this purpose we make use external sources which allow us to estimate the quality of the data collected in the EES. In our report, we list the main results of the comparisons we have drawn between the EES and these outside sources. The results are shown in the tables and figures below. Finally, we provide our main conclusions.

\footnotetext{
${ }^{1}$ Centre of Demography and Human Ecology, Institute of Socio-Economic Forecasting, Russian Academy of Sciences, Moscow

${ }^{2}$ Max Planck Institute for Demographic Research, Rostock

${ }^{3}$ The authors express their many thanks to Susann Backer for language editing and for her very helpful advice, to Jan Hoem for his valuable comments and to Vladimir Shkolnikov for his help in the organization of work with the databases, for fruitful discussions of the problem description, and for his profound advice given on several occasions.
} 


\section{External sources used. Features and limitations}

For the purpose of an external validation, we used various sources of social and demographic indicators in order to compare as many features as possible. The main sources are censuses and current social and demographic statistics. The demographic data available and nearest in time to the EES are the 2002 population census and the 1994 microcensus. However, it proved to be difficult to draw direct comparisons between the EES and the censuses since all data sources make use of different classifications of the social and demographic categories we are interested in. For instance, the categories of educational attainment used in the 1994 microcensus and the 2002 census differ from each other and from the categories used in the EES as well. Moreover, the branches of the economy in the current official statistics are different to those used in the EES. After several attempts, the following sources were used for external validation:

- the distribution of women by the number of children ever born to them, by age (from the 2002 population census (http://www.perepis2002.ru/ct/doc/TOM_12_04.xls));

- the distribution of children by year of birth, the marital status of the mother, and registration by means of either the mother's or the mother's and father's status of application for custody ${ }^{4}$ (Demographic Yearbook of Russia, 2005, Federal service of state statistics, Table 4.6, p. 237);

- the distribution of the midyear-employed by the branches of the economy

(http://www.gks.ru/free doc/2005/b05 13/05-06.htm);

- the distribution of the population by sex, age, and educational attainment tabulated from the individual database of the 1994 microcensus.

\section{Checking fertility}

Based on the EES, we calculated the number of women and the number of children ever born by 5year age groups of women at the time of the 2002 population census. In a second step, we compared the number of children ever born per 1000 women of a given age group with the 2002 census (Volume 12, Table 4; also see Figure 1 and Table A1 in the Annex of this document).

\footnotetext{
${ }^{4}$ For the latter variable, see below for further explanation.
} 


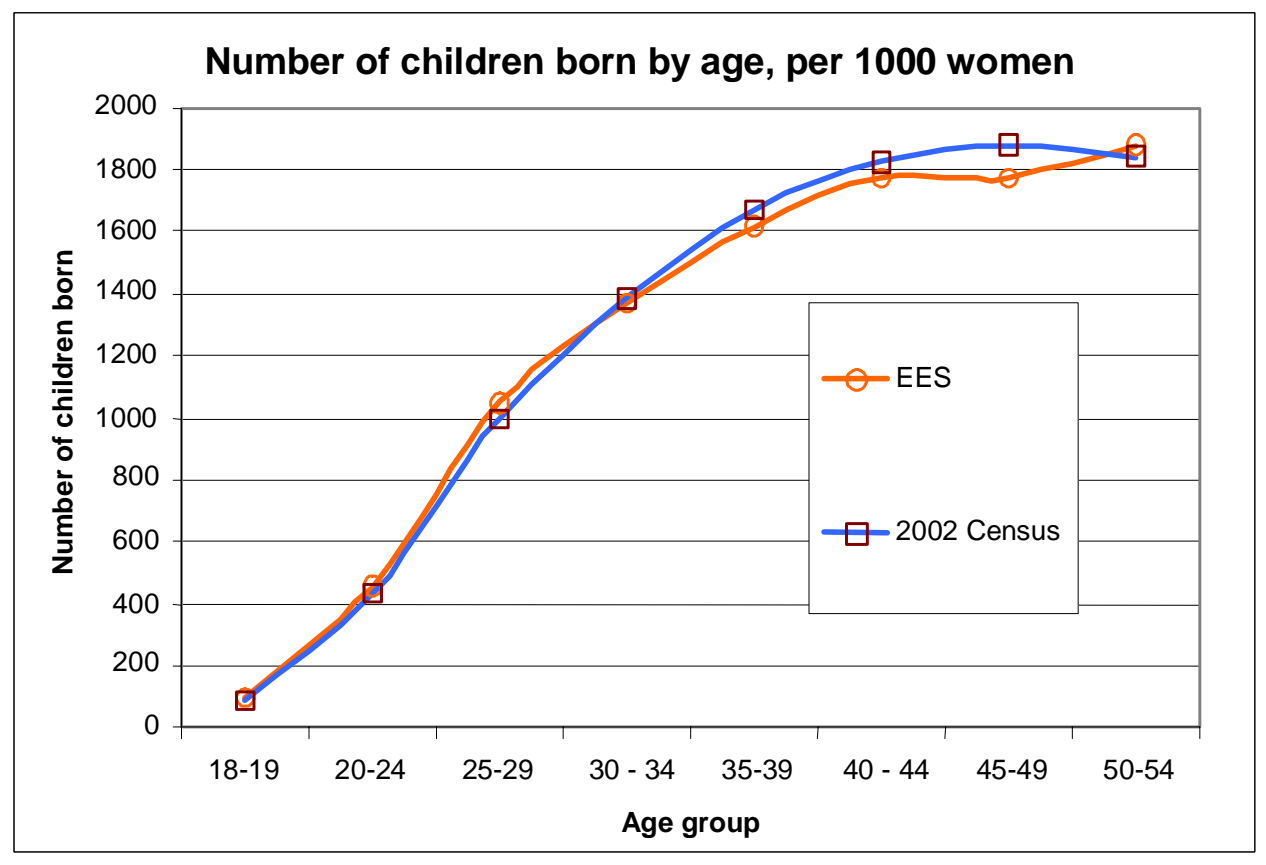

Figure 1. Number of children ever born by age, per 1000 women, 2002, EES and census.

The results given in Figure 1 indicate that female fertility and its age pattern up to the year 2002, if compared to the 2002 census, are very well represented by the EES - maybe with the exception of the age-bracket 45-49.

The EES also provides the opportunity to estimate "male fertility", that is the number of children reported by men. A tabulation of the number of children ever born by 5-year age groups reported by women and men in the EES is presented in Table A2 of the Annex and in Figure 2.

Predictably, male fertility is lower than female fertility in the age-groups below 35. For the higher age-groups, sex differences in the number of children reported tend to be smaller.

Unfortunately, there is no opportunity to compare the figures for men with current population statistics for Russia, since no data has been collected by fathers' age. However, for the last seventeen years, the Federal service of state statistics has been obtaining information sufficient to construct the following three categories of registration of children: (i) by married mother, (ii) by the joint application for custody of the child of the unmarried mother and the child's father, and (iii) by the application for custody of the child of the unmarried mother only. 


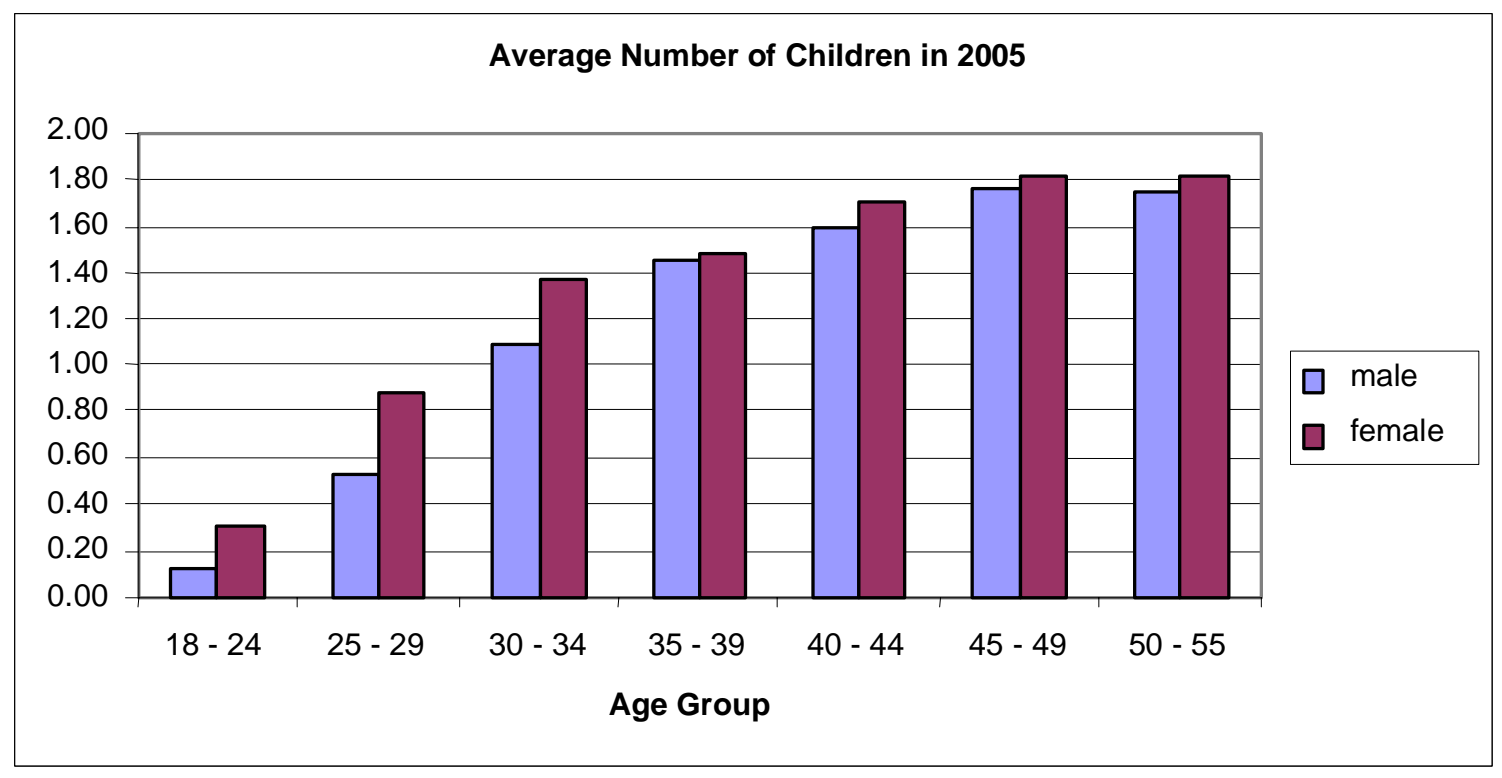

Figure 2. Average number of children ever born, by age, EES, male, female.

In the 1988-2004 period, the total number of children born in Russia was 26,048,840, of which $20,434,408$ were registered within marriage and 5,586,658 outside marriage. The last figure is made up of 2,492,059 children registered with joint parental application for custody and 3,094,599 registered with a custody application from the mother only ${ }^{5}$. Thus, 88 percent of all children were registered with joint parental custody application.

If we compute the male/female-ratio of the total number of children ever born among the respondents of the EES, differentiated by 5-year age groups, we also get a value of 88 percent (see Table A.2 in the Annex). According to this measure, the average fertility of the male respondents of the EES is 12 percent below the average fertility level of the female respondents. Strictly speaking, this indicator only provides a crude estimate of differences in male-female fertility. In particular, it does not take into account life course effects of a male's reproductive behavior.

In order to check fertility patterns also from a birth cohort perspective, we chose the 1960-64 birth cohort, which is the youngest female cohort which presumably had its childbearing behavior completed by the time the EES was conducted. To achieve comparability with a recent publication

\footnotetext{
${ }^{5}$ Calculated from: Distribution of children by year, marital status of mother, and registered by mother's or mother's and father's application. Demographic Yearbook of Russia, 2005, Federal Service of State Statistics, Table 4.6., p.237.
} 
(Demographic Modernization, 2006), we calculated the relative contribution of five-year age groups to the cohort's total fertility.

Figure 3 shows the age-specific fertility pattern of the 1960-1964 female birth cohort according to the EES and according to the official statistics of Demographic Modernization. In general, the two sources display a very similar age-specific fertility pattern. If at all, the EES tends to overestimate fertility for the age-groups 25-34, while it slightly underestimates the contribution of the 20-24 year olds to the cohort's overall fertility level.

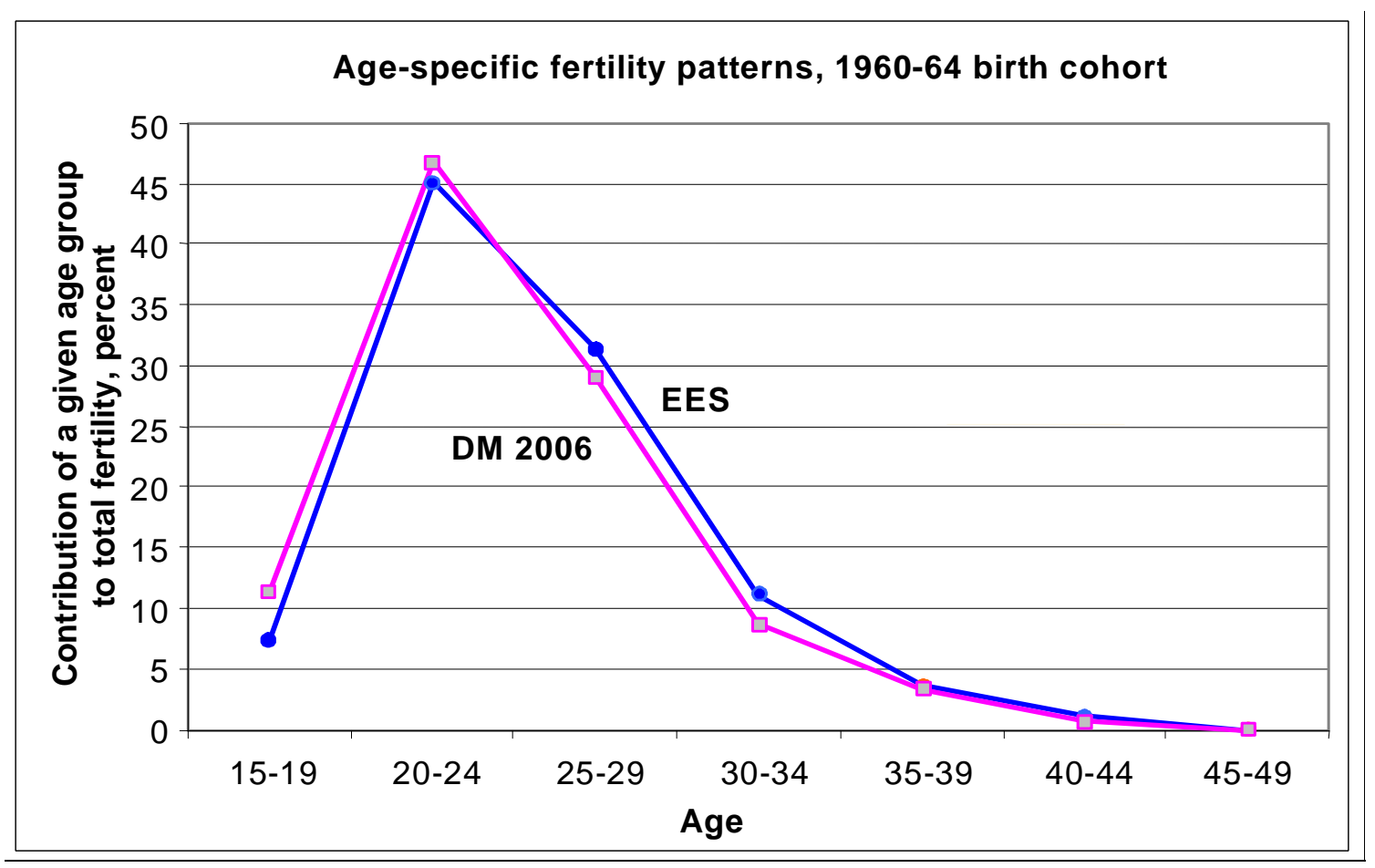

Figure 3. Age-specific fertility pattern of the 1960-1964 female birth cohort. Sources: tabulation of EES, Demographic Modernization, 2006, p. 185.

4. Checking the structure of the employed, by branch

For a comparison of the sectoral structure of employment, the year 2000 was chosen. The tabulation of the employed in the EES was restricted to branch of economy since the current official statistics do not provide more detailed demographic information (e.g. the age-sex structure of the 
employed). Another problem to deal with stems from the fact that the set of branches in the EES and current statistics differ from each other. Therefore we had to aggregate some branches into broader groups. The rules of correspondence between the sets of branches we established are presented in Table 1.

Table 1. Branches of economy used in the comparison.

\begin{tabular}{|c|c|c|}
\hline Short name & EES codes and names & Current statistics \\
\hline Agriculture & $\begin{array}{l}71 \text { (Agriculture, hunting and forestry, fishery and } \\
\text { fish-breeding) }\end{array}$ & Agriculture + Forestry \\
\hline Manufacturing & 72 (Mining) + 73 (Manufacturing) & Industry \\
\hline $\begin{array}{l}\text { Social } \\
\text { provision }\end{array}$ & $\begin{array}{l}74 \text { (Production and distribution of electric energy, } \\
\text { gas, water) }+83 \text { (Compulsory social provision) }+ \\
84 \text { (Other communal and personal services) }\end{array}$ & $\begin{array}{l}\text { Housing and public utilities, } \\
\text { non-production sectors of } \\
\text { personal social services }\end{array}$ \\
\hline Construction & 75 (Construction) & Construction \\
\hline Trade & $\begin{array}{l}76 \text { (Wholesale and retail trade, repair services, } \\
\text { hotel business and catering) }\end{array}$ & $\begin{array}{l}\text { Wholesale trade, retail sales, } \\
\text { catering }\end{array}$ \\
\hline Transport & $\begin{array}{l}77 \text { (Transport, mailing, communication and } \\
\text { telecommunication services) }\end{array}$ & Transport + Communications \\
\hline Banking & $\begin{array}{l}78 \text { (Banking, insurance, marketing and other } \\
\text { financial activity, real-estate, legal, leasing } \\
\text { services, information technologies, etc.) }\end{array}$ & Finances, credits, insurance \\
\hline Administration & $\begin{array}{l}79 \text { (State administration of _federal_level) }+80 \\
(\text { _regional_) }+81 \text { (_municipal_) }\end{array}$ & Administration \\
\hline Education & $\begin{array}{l}85 \text { (Education, science/academy) }+87 \text { (Culture } \\
\text { and arts) }\end{array}$ & $\begin{array}{l}\text { Culture and arts }+ \text { Science and } \\
\text { scientific service }+ \text { Education }\end{array}$ \\
\hline
\end{tabular}


The empirical results concerning the branch-specific structure of the employed population are displayed in Figure 4. Please note that in the figure only those branches are included for which we could establish a correspondence rule.

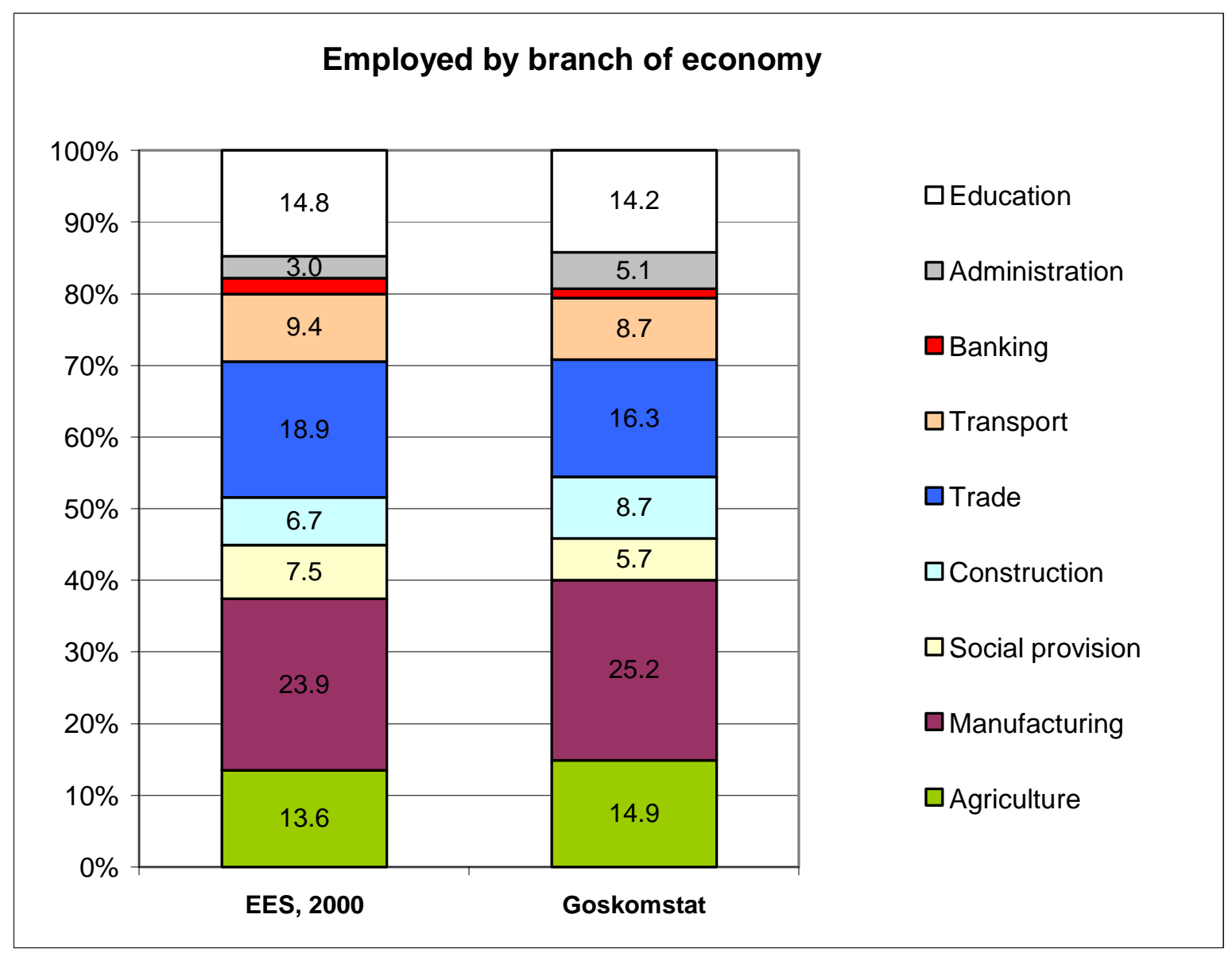

Figure 4. Employed by branch of economy, 2000, EES and Goskomstat. Percentages of the branches involved.

The illustration shows that the branches in the sectoral structure differ only within a range of 2-3 percent for each branch in the worst cases. We obtain a correct representation of major branches such as Manufacturing, Trade, and Education. 


\section{Checking educational attainment}

We also made a tabulation of the EES by sex and educational attainment. A comparison was made between the EES tabulation and a tabulation of the 1994 microcensus. The number and sets of educational attainment are different in the two surveys, which is why only three categories could be used for comparison: tertiary, secondary, and below secondary education.

To make the comparison between the EES and the microcensus of 1994 feasible, we only considered the educational degrees obtained by EES respondents by 1994.

The percentages of educational attainment achieved by males and females are given in Figures 5 and 6. The figures show that, in the EES, men and women who have attained a tertiary degree are well represented. Men and women who have attained less than secondary education are overrepresented in the EES.

We recommend a deeper examination of the educational histories of the EES-respondents, an examination that takes into account that, in the EES, educational histories and degrees have only been recorded starting from the year at which the respondent turned 17. Information from the Russian GGS on the respondents' highest educational level might be used to estimate the proportions of EES-respondents who had already attained their highest secondary educational degree before they turned 17 years of age. ${ }^{6}$

Having a closer look at the age distribution of the graduates from higher (tertiary) education, we can easily see a good correspondence between the two sources for both males and females (see Figures 7 and 8). The only exceptions are male graduates in the age-bracket 30-34. They are slightly over-represented in the EES.

\footnotetext{
${ }^{6}$ GGS-respondents were asked about their highest educational level obtained. For educational episodes beyond general schooling, respondents were also asked about the month and year of graduation.
} 


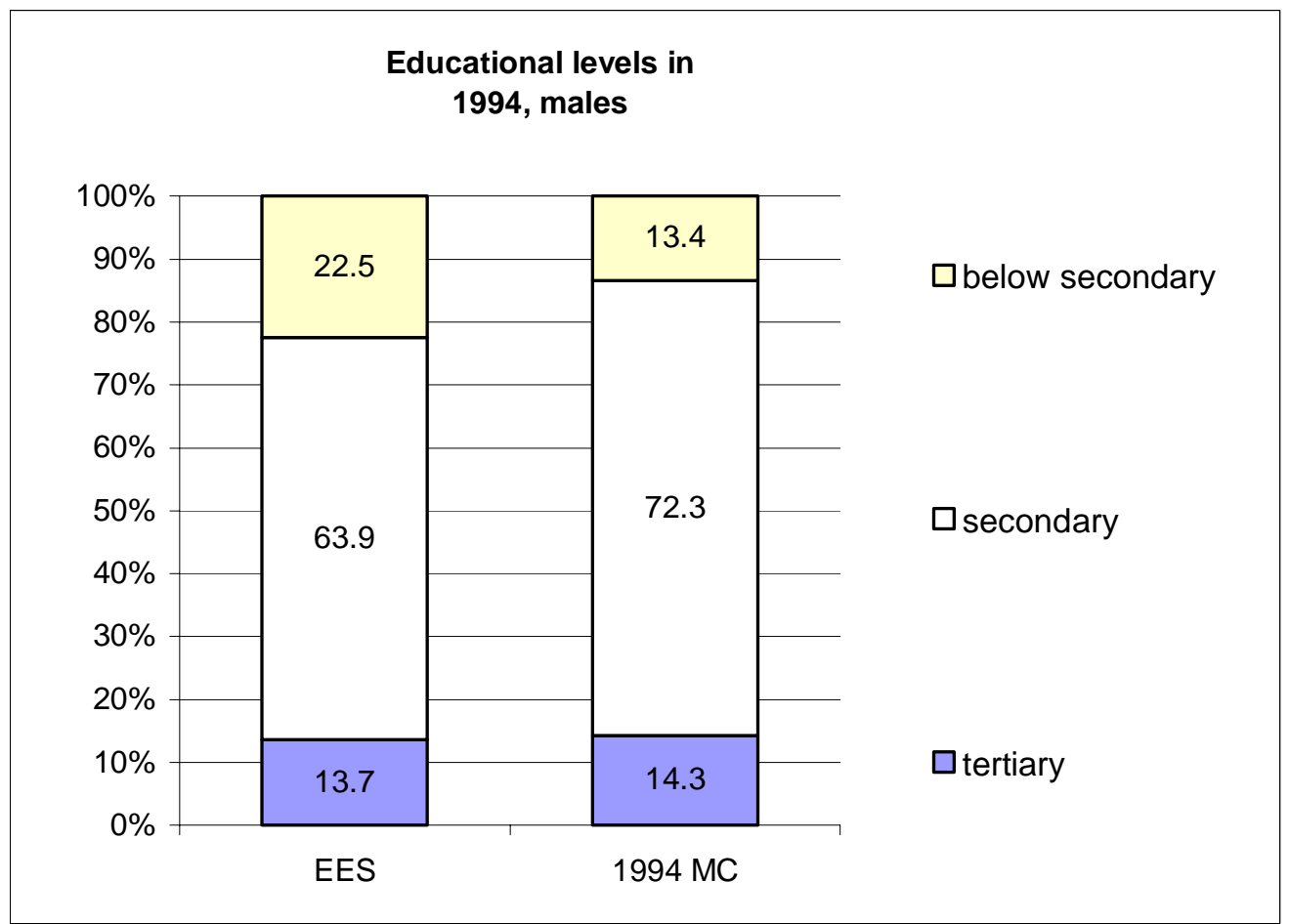

Figure 5. Educational attainment up to 1994 according to the EES and 1994 microcensus, males.

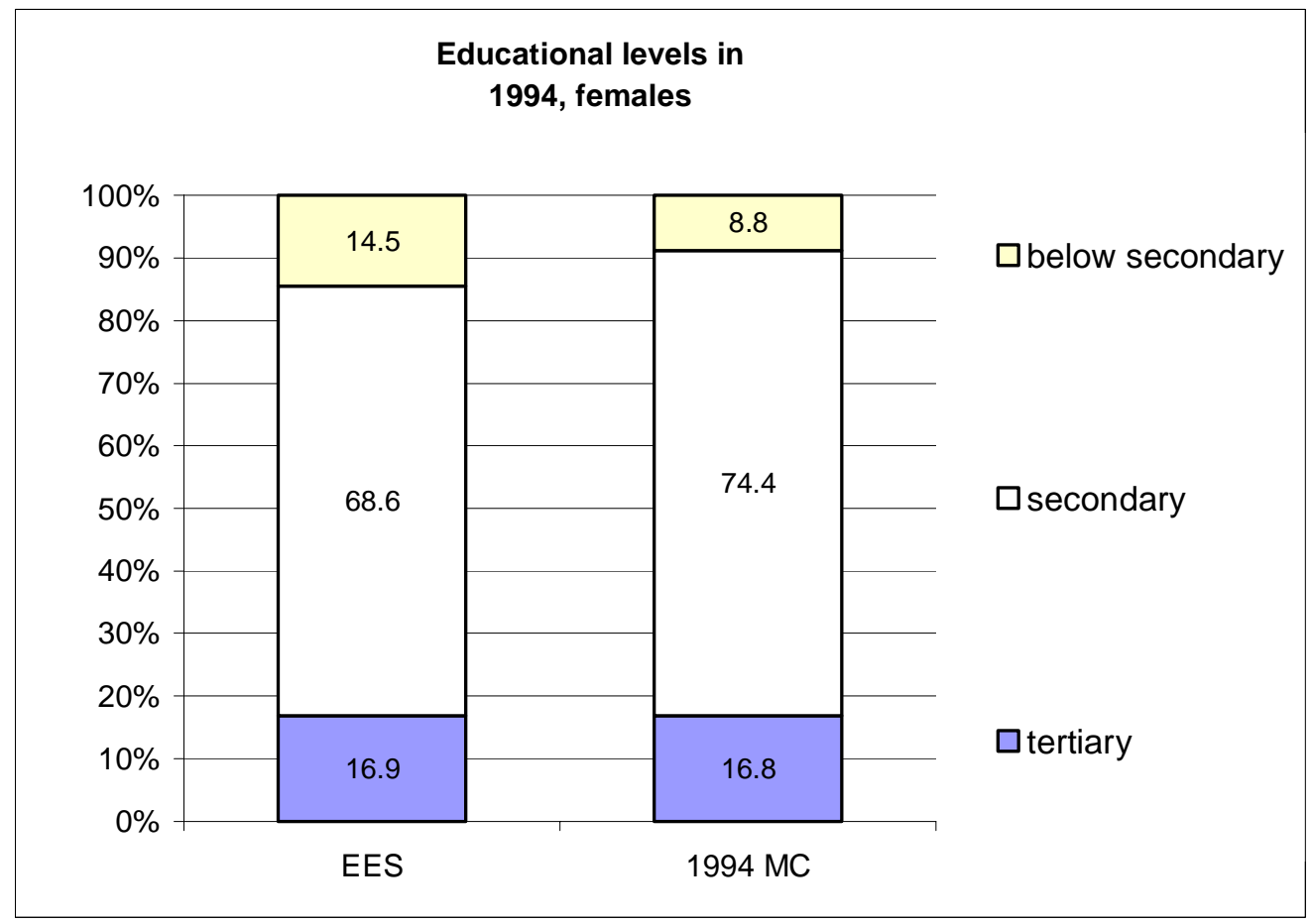

Figure 6. Educational attainment up to 1994 according to the EES and 1994 microcensus, females. 


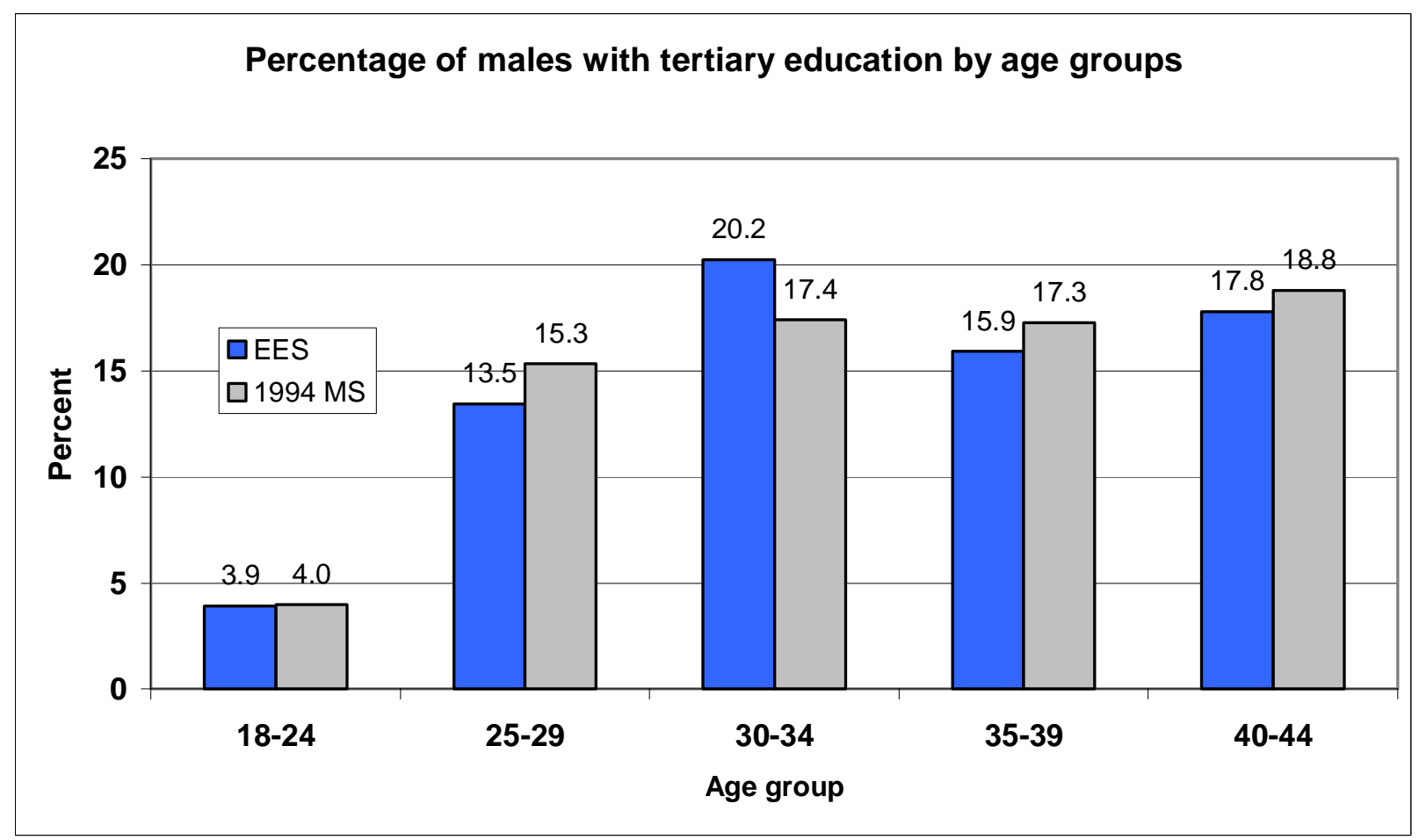

Figure 7. Percentage of males with tertiary education up to 1994 , by age.

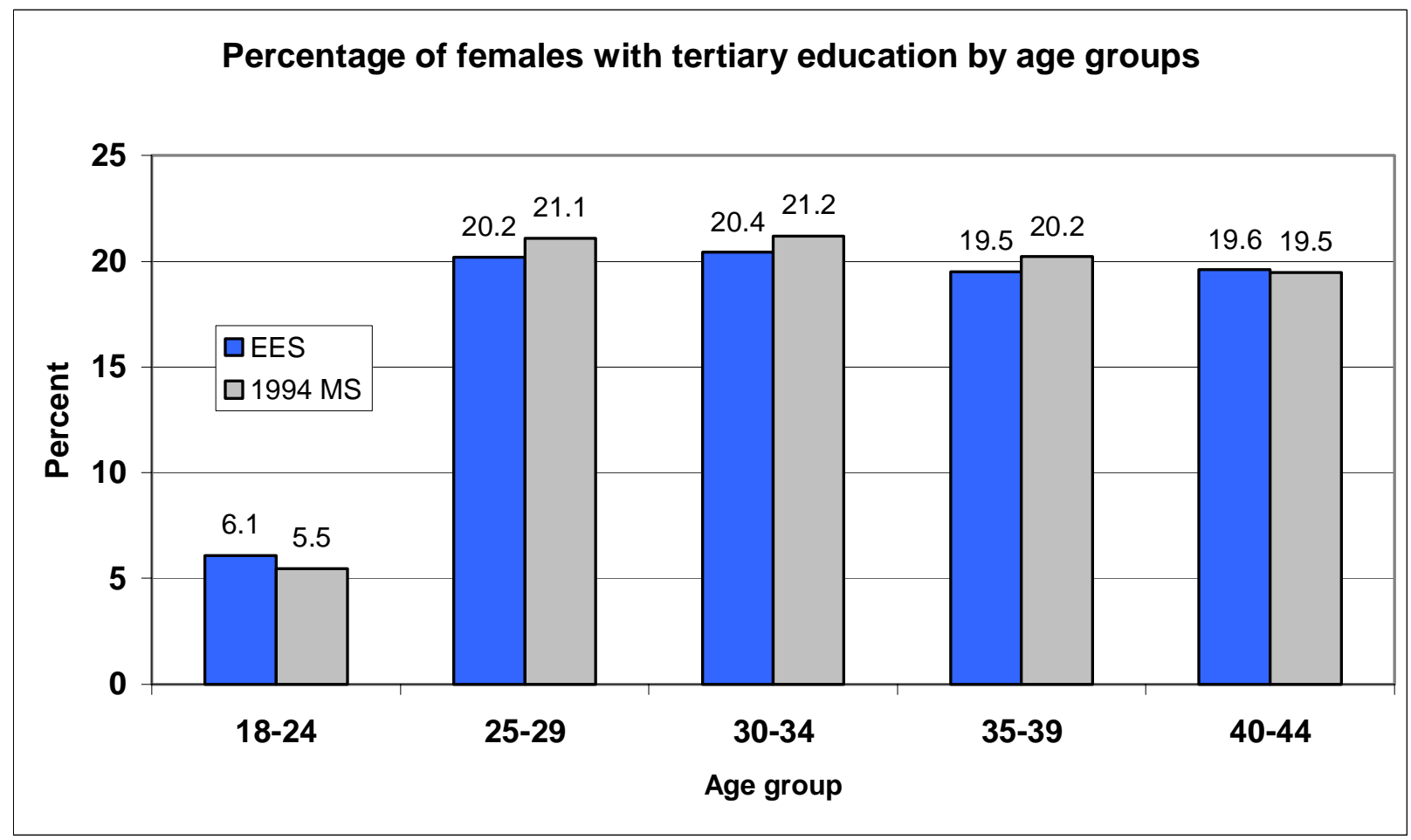

Figure 8. Percentage of females with tertiary education up to 1994 , by age. 


\section{Conclusion}

The following conclusions can be drawn regarding the data quality of the EES, based on the results of the external validation of the EES.

1. Most of the external validation showed a rather good general correspondence of the results obtained by comparing the EES with the results obtained from official Russian statistics.

2. In particular, female fertility and its age patterns displayed very good coincidence with the 2002 census.

3. The age-specific fertility patterns of the birth cohorts displayed a good agreement of the EES with the other sources.

4. The total difference between male and female fertility showed a good correspondence to the current registration of children.

5. The structure of the employed by branches of economy displayed a rather good coincidence with current social-economic statistics - taking into account different definitions given to the branches.

6. The structure of the population by educational attainment did not display sufficient closeness to the 1994 microcensus; there was an over-representation of the lower educated. However, the age and sex structure of the population with tertiary education proved to be rather good. 


\section{Sources}

- Project “EES”. Education and Employment. Interviewer's Questionnaire. Moscow, 2005.

- Mean number of children ever born having different educational attainment by the regions of the Russian Federation. The 2002 population census. (http://www.perepis2002.ru/ct/doc/TOM_12_04.xls).

- Distribution of midyear employed by branches of economy (http://www.gks.ru/free doc/2005/b05 13/05-06.htm)

- Distribution of children by year, marital status of mother, and registered by mother's or mother's and father's application. Demographic Yearbook of Russia, 2005, Federal service of state statistics, Table 4.6., p.237

- The 1994 microcensus of the Russian Federation. Individual micro database.

- Demographic Modernization: Демографическая модернизация России, 1900-2000. Moscow, 2006. (http://demoscope.ru/weekly/2005/0225/biblio01.php). 


\section{Annex}

Table A1. Number of children ever born, by age, per 1000 women, EES and 2002 census.

\begin{tabular}{|c|c|c|c|c|}
\hline \multirow{2}{*}{ Age } & \multicolumn{3}{|c|}{ EES } & \multirow{2}{*}{$\begin{array}{c}\text { 2002 census. } \\
\text { (Volume 12. Table 4) }\end{array}$} \\
\cline { 2 - 5 } & $\begin{array}{c}\text { Number of children } \\
\text { born }\end{array}$ & $\begin{array}{c}\text { Number of } \\
\text { women }\end{array}$ & $\begin{array}{c}\text { Children per 1000 } \\
\text { women }\end{array}$ & 89 \\
\hline $18-19$ & 16 & 160 & 100 & 438 \\
\hline $20-24$ & 190 & 417 & 456 & 993 \\
\hline $25-29$ & 494 & 471 & 1049 & 1386 \\
\hline $30-34$ & 694 & 505 & 1374 & 1668 \\
\hline $35-39$ & 867 & 535 & 1621 & 1878 \\
\hline $40-44$ & 1243 & 700 & 1776 & 1845 \\
\hline $45-49$ & 1118 & 630 & 1775 & 1883 \\
\hline $50-54$ & 855 & 454 & & \\
\hline
\end{tabular}

Table A2. Number of children ever born, by age group (male, female), EES 2005.

\begin{tabular}{|c|c|c|}
\hline Age group & Female & Male \\
\hline $18-24$ & 0.31 & 0.12 \\
\hline $25-29$ & 0.88 & 0.54 \\
\hline $30-34$ & 1.38 & 1.08 \\
\hline $35-39$ & 1.49 & 1.45 \\
\hline $40-44$ & 1.71 & 1.59 \\
\hline $45-49$ & 1.81 & 1.75 \\
\hline $50-55$ & 1.81 & 1.75 \\
\hline Average & 1.34 & 1.18 \\
\hline \multicolumn{2}{|c|}{ Male / Female, Percent } & 88 \\
\hline
\end{tabular}

